\title{
Mapping Sustainable Development Goal Indicators for Pakistan: Way Forward
}

\author{
Izza Aftab \\ Information Technology University \\ Maha Kamal \\ Information Technology University \\ Anum Irfan \\ Information Technology University
}

This paper aims at developing tools for data collection for the successful implementation of the Sustainable Development Goals in the light of data poverty in Pakistan. To this end, 232 SDG indicators were individually mapped with individual questions from Pakistan's national data sources. After a comprehensive mapping exercise, the data was further broken down by the UN Statistics Division 3 Tiers. Recommendations were made on specific indicators that fall under Tier I where data was still found missing under SDG 7 and 9 and a collation of disparate sets of data was proposed. The paper concludes with policy implications for structured data collection for SDGs in Pakistan.

Keywords: sustainable development goals, measurement, data poverty, SDG 7, SDG 9, energy, firms, pakistan

\section{INTRODUCTION}

Since the adoption of the Sustainable Development Goals (SDGs) by the United Nations in 2015, the trajectory of individual nation-states on the issue of measurement of the goals has been varied. Issues that have affected the direction of successful implementation of the SDGs include data poverty, and the actual evidence needed to measure progress. While on a regional and national level, estimates can still be made for progress by countries like Pakistan. However, on a subnational level, issues of data on the SDGs under four criteria availability, quality, granularity and accessibility of data.

On a national level, Pakistan was one of the first countries in the world to endorse the 2030 Agenda for Sustainable Development (UNDP \& Pakistan Ministry of Planning, Development and Reform, 2018). The country carried forth that commitment by a formal ratification in the country's Parliament in February 2016. In terms of translating diplomatic parlance to action on the ground, on a legislative front, efforts were made towards mainstreaming SDGs in Pakistan's local context, and the relevant statistical bodies such as the Pakistan Bureau of Statistics were mobilized for action. 
Moreover, specific SDG Units were created at a Federal level (National) and Provincial Levels in the provinces of Punjab, Sindh, Khyber Pakhtunkhwa, Baluchistan and Gilgit-Baltistan (UNDP \& Pakistan Ministry of Planning, Development and Reform, 2018). A national report from the Federal SDG Unit on data gaps mapped existing sources of data on all SDGs through the United Nation Statistics Division "tier" classification (United Nations Development Group, 2018) and then through Pakistan's own coding system developed that sub-categorises goals on basis of national priorities in terms of urgency_(UNDP \& Pakistan Ministry of Planning, Development and Reform, 2018).

However, existing reports and literature (UNDP \& Pakistan Ministry of Planning, Development and Reform, 2018)_(Ghaus, 2016)_(Gul, 2018) take a macroscopic view and focus on engaging institutional bodies, engaging stakeholders and develop capacity. Aggregate data sources were available at the global level, for example, through UN Statistics, World Bank Development Indicators, at the regional level through the Asian Development Bank and at the national level through relevant ministries in Pakistan, specifically the Ministry of Planning Development and Reform. Moreover, the specific challenges follow from a little known and usually misunderstood fact about Pakistan that is the devolution of key subjects from the federal to the provincial governments. This devolution, referred to as the $18^{\text {th }}$ Amendment to the Constitution of Pakistan (National Assembly Pakistan, 2010) which impacts not only data collection (specifically increased challenges on data granularity) but more importantly Pakistan's success in achieving the SDGs. While the devolution is beyond the scope of this paper, it is important to be cognizant of it as the reader contextualizes Pakistan's data poverty. This paper aims to fill the gap left by existing studies that analyse SDGs on a sub-national level.

This paper addresses these challenges and asks: first, how far does data poverty exist for the SDGs in Pakistan. Second, do specific Sustainable Development Goals, classified as tier 1 show large variation in data under the four criteria? Third, how could gaps on goals within tier 1 be addressed to tackle the measurement problem and improve the data collection process? These questions were addressed through a three-pronged approach.

First, following the global indicator framework of the UN Statistical Commission, as adopted by the General Assembly in 2017 (United Nations Development Group, 2018), 232 SDG indicators were individually mapped with relevant questions through an exhaustive review of Pakistan's national data sources including the Pakistan Social and Living Standards Measurement (PSLM), the Multiple Indicator Cluster Surveys (MICS), Pakistan Demographic and Health Survey (PDHS), Labour Force Survey (LFS), Pakistan Economic Survey etc. After a comprehensive mapping exercise, the data was further broken down by the UN Statistics Division (2018) Tiers. Second, two tier 1 SDGs were analysed under a measurement framework of availability, quality, granularity and accessibility of data, as a proxy of data poverty in Pakistan to demonstrate the gaps within SDGs of the same classification, within goals themselves, and recommendations were suggested for improved measurement of the goals. This framework allows a clear analysis and application to specific SDGs, and may demonstrate how countries with similar problems in measurement of SDGs may not only recommend changes to existing national surveys, but also suggest a framework for analysis to draw insights for policy gaps.

The paper is presented in four sections. Section one looks at the literature review and gives an overview of measuring SDGs in the light of data poverty in Pakistan; Section two focuses on methodology and data, describing the data that will be critical to measuring SDGs effectively (namely

goals 7 and 9); Section three focuses on the findings of our paper; Section four concludes the paper and gives recommendations on the way forward.

\section{LITERATURE REVIEW}

The importance of the Sustainable Development Goals (SDGs) is established and accepted by incorporating it as part of the national agenda framework of Pakistan, thus showing commitment to the cause. A big part of attaining the SDGs is a country's ability to track their progress and institutionalize them where progress is lagging. 
In this section, we present a brief literature review documenting the importance of SDGs, their disaggregation and data gaps that exist in Pakistan.

For the success of the SDGs, it is important that they are time-bound, specific and measurable. The SDGs enhance mobilization of the global community through strengthening networks across all sectors, regions and countries who share their achievements on specific indicators. The need to follow goals allows consistent effort oriented towards what matters rather than understanding issues in a rather disparate and complex environment (Gurbo, 2017). Pakistan embedded the 2030 agenda as part of its National Development Framework and established linkages with Vision 2025 showing its strong commitment to achieving SDGs (Gul, 2018).

SDGs aim to encapsulate a triple bottom line approach to human welfare by focusing on economic growth through ensuring environmental protections and social inclusion and needs such as education, healthier lives and achieving gender equality (Sachs, 2012). This integrated framework has led SDGs to be universally applicable and indivisible in nature, aiming to overcome the many challenges faced by the Millennium Development Goal (MDGs) that was viewed as a 'North-South aid agenda' hinged upon a narrow view of development_(Jacob, 2017) SDGs are a commitment of the international community and data that is trusted and accurate will be considered as a key to ensure that the Agenda is on track (UNESCAP, 2017).

2030 Agenda for Sustainable Development in 2015 has led the international community to develop a more holistic approach towards the challenges of implementation and monitoring progress. Through data based reporting, countries can gain insight into relating national priorities with SDGs, data ecosystems can be improved to ensure that countries strengthen their internal technical capacity to achieve SDGs (Ariss \& Manley, 2018). The SDGs present a universal agenda that breaks away from the dichotomy of developed and developing countries, yet the agenda calls for tailor-made approaches supported in conjunction with global actions (UNESCAP, 2016). The 2030 Agenda calls for an international realization of the need to shift away from a 'business as usual' model in terms of developing statistical capacity and data collection (Judd, 2016).

Despite 15 years of MDG implementation, data poverty exists in terms of quality and availability across most indicators. At this juncture, MDG lessons can enhance implementation of 2030 agenda. Empirical research that analysed data gaps in MDG in conjunction to actual performance achievements revealed that larger the data gaps in measurement, the worse performance on actual MDG progress by using the MDG indicators

Database; despite controlling for national statistical capacity_(Jacob, 2017) (Chen, Fonteneau, \& Jütting, 2013) argue that data points of MDGs are often adjusted for international comparability, furthermore nearly a third of indicators are lacking for half of the countries. The key message to be derived from MDGs limited success, was to closely lay a foundation for evidence based policy for the 2030 Agenda.

The MDGs had already laid the groundwork of raising awareness on the importance of developing statistical capacity and shed light on data poverty in most developing countries. It is crucial to derive lessons from MDG implementation experience in Pakistan. Non-availability and unreliable data was considered as the most prominent challenge in measuring MDGs. For instance, baseline data was derived from unreliable household surveys from 1990 that lacked reference on registered birth and death records. In Pakistan, reports on MDG progress were difficult to interpret precisely because it was based on undocumented assumptions and poor quality data. The success of the ambitious 2030 Agenda is interdependent on measuring progress through timely, reliable and granular data. Implementation of SDGs through measurement is crucial for acting as facilitator of standards and help enhance accountability and enable impact assessments to be carried forward based on evidence. 'Data' is featured as a prominent feature required as the 'life-blood of decision-making 'and a tool to track SDG Implementation. Answers to questions such as 'How many people have access to electricity or clean water' per se can act as a baseline for monitoring SDG progress and where a country stands in terms of implementation (Ariss \& Manley, 2018). The complexity and interconnection of 17 targets and corresponding indicators will challenge LDCs particularly. The need to provide timely, accessible and 
reliable open data will not only impact policy-making based on the needs of citizens but also empower individuals within a community to make informed decisions (Asghar \& Umar, 2017).

Previous lessons from MDGs have led to incorporation of means of implementation in SDGs described as "mapping of all types of resources needed for the achievement of SDG targets," a recurring constraint was lack of disaggregated data that hindered implementation of policies and programmes in terms of SDG progress.

Mapping SDG Indicators is considered as a first step to move from nationalization to localization at grass root levels. An example is the 'Data Ecosystem Mapping project' in Swaziland that aimed to strengthen Central statistics office by guiding the new national strategy in terms of statistical development and identifying key entry points for other non-official data stakeholders (UNDP, 2016). In a data mapping case from Bangladesh that mapped all SDG indicators revealed that $80 \%$ of indicators had available data for Goal 1, 7 and 8 whereas serious data poverty was observed in environment related goals and Goal 5 on quality education (Rahman, Khan \& Sabbih, 2015). A regional comparison of lower-middle income countries revealed further challenges faced at a global level in measuring SDG through data. The Government of India realizes the non-availability of data at sub-national levels coupled with periodicity issues and incomplete coverage of administrative data. The failure to measure MDGs in India, despite having well-established CSOs, was attributed to general statistical data that did not meet specific requirements (Dickens et al, 2019). Therefore, developing a system of implementation, measurement and monitoring is of paramount importance (David, 2018).

In a similar vein, an evaluation of the state of data for SDGs in Bangladesh (Rahman, Khan \& Sabbih, 2015), revealed gradual improvements in data production, despite gaining ground towards the data revolution, data is not available for 42 indicators from existing surveys examined. Furthermore, the data if available is of varying degrees in terms of quality assurances, in terms of accessibility, comparability and coherence. The reason for data gaps in lower middle income countries (LMIC) has been attributed to constraints on National Statistical Offices (NSOs) in terms of outdated legislation, lack of statistical data awareness, weak cooperation between data producers and users and an inability to adapt international guidelines in terms of classification, definitions and standards that results in non-comparable data (Judd, 2016). The two most common factors that have hindered further data dissemination are issues revolving around confidentiality and misuse of data. Government of Bangladesh has addressed this constraint through public private partnerships in data that is frequently used by policy-makers. Furthermore, Statistical Act 2013 is not proactively followed by the Bangladesh Bureau of Statistics (BBS) in terms of data validation procedures this demonstrates lack of statistical capacity building among stakeholders (Rahman, Khan \& Sabbih, 2015). It is argued that in South Asian countries, accurate tracking of all 17 goals and associated 169 indicators, will be beyond the capacity of statistical systems. For instance, data collection of even the most elementary form of administrative data such as civil registration of birth and death is lacking, where all South Asian countries, except Sri Lanka have less than half coverage of births registered. This can have severe implications in measuring mortality indicator (8.5) (UNESCAP, 2016).

The Government of India has been bridging the measurement gap through identifying new resources, for instance the Labour Force Survey (LFS) that is used to measure employment related indicators will be conducted on a quarterly basis for urban areas in India (David, 2018). Furthermore, time-use surveys are used to measure gender and economic disparities. Initiatives on modernizing existing data collection methods have begun including e-dissemination, space technology for household surveys. National efforts for measuring SDGs will require global technical assistance or replacing existing methodologies this is crucial in the realm of global indicators that are not directly measurable at a country level. An initial review of 231 SDG indicators revealed that only 14 percent indicators were of measurable nature (Dickens et al, 2019).

Moreover, the problem of granularity appears to recur in the literature. Granularity, of data, is vital since disaggregated data can enable the formulation of effective policies for targeting specific disadvantaged groups and geographical areas in the country (Patole, 2018).

Most countries do not collect regular data for more than half of the global indicators. Accurate and timely data is lacking for marginalized segments of the population, exacerbating their vulnerable position. 
National data, compiled by international agencies is often adjusted for comparability purposes, where lacking data is estimated. Even though aggregate figures allow progress to be tracked, the demographic features of individual countries are blurred. Aggregate figures from countries as presented by the United Nations Statistics Division obscures the reality, that data is unavailable to monitor implementation of developmental policies_(UNESCAP, 2019).

Furthermore, data can transform legislation, as revealed in El Salvador, where 28 percent of all girls are married before 18, this led civil organizations to understand a legal loop that allowed girls to marry with parental consent, often resulting in girls marrying their rapists. Another example is data gathered in Kenya on women's share in land ownership, encouraged men to take joint land entitlements with their spouses_(Equal Measures 2030, 2018). A study conducted in Senegal, which has highest proportion of deprived children, aimed to highlight disaggregation of 50 SDG indicators that have an impact on children. In terms of the criteria on data availability 42 percent were not reported at a regional level whereas at municipal level, no data was provided. The reason for such discrepancy was attributed to lack of appropriate mechanisms to collect reliable statistics. Furthermore, there was an inherent lack of data being granular where more than 90 percent of indicators were not disaggregated, the situation corresponds to disaggregation by gender and age. Data accessibility, was another criterion that revealed data was not shared between different stakeholders, subject to hierarchal barriers and authorization required, this contradicts the aim to make data more transparent. Thus, data available, is trapped in a system that makes it inaccessible_(Faye \& Kane, 2018).

The limited nature of disaggregated data on sub-national levels limits effective monitoring locally, especially in culturally diverse countries such as China and India where challenges persists in terms of specific goals such as goal 10, that focuses on within country inequality. This issue is being addressed through the paradigm of SDG 'localization' as a unified framework is to compare performance that remains a challenge across sub-national regions.

Another empirical study of measuring SDGs through the lens of 'leaving no one behind', aims to develop a disseminated framework through choosing 78 outcome-based indicators that are quantifiable at country-level. The study presents Canada's progress as an example, as despite having exceptional performance on most goals, some consistent 'leaving behind' patterns were revealed in certain population segments, for instance in terms of Gender equality, the framework revealed that only 36 percent of the managerial positions will be filled by women, further extrapolating this gender gap it was revealed that 5.5 million women are being excluded from equal opportunities in various domains. This multi-step framework helps to identify how useful country-level measurement is if accounted for people who are invisible or under-represented in aggregated data_(Rasmussen \& McArthur, 2019).

The rationale of choosing goal 7 based on access to reliable and clean energy is largely crucial as source of electricity can have severe implications on well-being and on the environment. Stable electricity supply will foster economic activity. Furthermore, goal 9 has been synergized with various other goals especially poverty eradication through social mobility and employment (United Nations, 2017).

In assessing the principle data issues in all 17 goals, the paper highlights how goals 7 (Energy) and 9 (Industry), are limited in terms of indicator concept understanding by respective countries, furthermore main sources of data is either administrative or business data which makes disaggregation rather difficult (Kroll \& Teksoz, 2017). In taking Pakistan as case study for goal 7, it was found that the main source of reliable statistics was the Pakistan Energy Yearbook (2018) that does not disaggregate data but rather present a national holistic framework of the energy sector. Pakistan's average score on goal 7 and 9 was 24.8 and -28.6 respectively, despite being useful for igniting policy debate, these scores need to explain further discrepancies in terms of each indicator (Kroll \& Teksoz, 2017).

Official statistical institutions along with evidence-based measurement development aims to contribute to SDG performance measurement (Miola \& Schiltz, 2019). One such example is the SDG index that conducts an annual SDG performance on country-level through aggregate statistics to allow cross-country comparisons on performance indicators. This is expressed as a percentage of achievement and the relative distance to invariant targets. Pakistan ranks 54.9 on the composite index and is ranked 126 out of 156 on the SDG global ranking (Jeffrey Sachs, Kroll, Lafortune, \& Fuller., 2018). However, 
despite being an overall measure of progress of the country, it is limited in highlighting the internal discrepancies. This is largely attributed to lack of data and infrequent nature of data provided in terms of periodicity that makes it rather difficult to provide scores annually. Others have argued that there are inherent flaws in using composite indices as a measure of gauging social progress, largely as it values practicality over quality of data and therefore it is argued that it is "not credible to contend that any single index could capture all that matters in all settings" (Kanbur, Patel, \& Stiglitz, 2015, p. 8).

Existing national statistical capacity can be enhanced through substantial investments in not only disaggregation but also on geospatial data infrastructures and adapting new methodological dimensions to reduce costs of existing method (Ghaus, Ahmed, Khan, Manzoor \& Sohaib, 2016). The main challenge for statistics is to manage a data revolution aligned with SDGs priorities of broadening and deepening production and dissemination of data (UNESCAP, 2016).

An evaluation of national statistical systems (NSSs) in Asia and Pacific region revealed the challenge posed to NSS to report on more than 230 indicators in official SDG framework, indicators required dissemination in terms of age, sex, income and location. Even though disaggregation in terms of location was available widely in the Asian context, granular data is of limited nature in terms of sex and is often non-existent for special minorities such as indigenous groups (UNESCAP, 2017).

The Pakistan Bureau of Statistics (PBS) is considered as the key principal institution for data collection and dissemination. National level household surveys used in Pakistan such as Multi-Indicator Cluster Surveys (MICS), Pakistan Demographic Health Survey (USAID, 2018) and as Pakistan Social Living Measurement Survey (PSLM) are often used as the main source of information for SDG monitoring particularly social indicators (Pakistan Bureau of Statistics), (Umar \& Asghar, 2018). They are considered limited in terms of coverage and collection is inconsistent, for instance DHS is collected every 5.88 years and data provided by these surveys lacks comparability. Furthermore, approximately 30 indicators are covered.

However, these surveys have aimed to provide a baseline for Pakistan (Gul \& Mantegazza, 2018). Hassan (2016) proposes that data for 18 indicators can be provided at district-level through additional questions added to existing monitoring mechanisms. Considerable overlapping of questions was revealed in household surveys such as PDHS and MICS, however each survey lacks in terms of coverage, where LFS provides only provincial data, MICS provides district-level data but is limited in terms of provinces covered such as Punjab. (UNDP \& Pakistan Ministry of Planning, Development and Reform, 2018)

Pakistan included the SDG Agenda 2030 as a National Development Agenda of the country, after which efforts to mainstream SDGs at both national and provincial level have begun (Umar \& Asghar, 2018). The federal and provincial government has committed US\$1.5 million for financing SDG Support units, the provincial governments will allocate a fifty percent share of the total project budget of US\$35 million for implementation including improved data and reporting mechanism (United Nations Development Group, 2018)

The 2030 Agenda has urged countries to develop a national data infrastructure, because official statistics and disseminated administrative data is viewed as a public good. Politicians do not understand the role of soft infrastructure that is considered as an unavoidable cost rather than a national asset, that leads to public sector efficiency and help design public policy through evaluation and implementation by linking various stakeholders (MacFeely, 2018).

An overarching ambition of the Agenda that is 'leave no one behind', is not financially viable, for even the most efficient statistical systems, therefore this becomes a global statistical challenge to develop data granularity, that prioritizes measurement of vulnerable rather than allocating resources to disaggregation (Umar \& Asghar, 2018) (MacFeely, 2018). PARIS21 (2015-11), has provided an estimate of the funding gap to be increased from US $\$ 1$ billion to 1.25 billion by 2020 to develop statistical capacities. An SDG monitoring framework can cost $\$ 1.5$ billion per target, measurement of SDG alone can cost 12.5 percent of total development aid_(PARIS21, 2015). Gender and rural-urban discrepancies further aggravates the issue of measuring SDGs through the lens of inclusivity as visibility in data of different segments becomes questionable encompassing sustainable development leads to understanding 
development that is equitable in Pakistan as revealed through efforts to construct a provincial SDG index in Pakistan (Umar \& Asghar, 2018).

The federal government has aimed to build capacity through localization of SDGs at provincial level and coordinate with respective ministries for monitoring SDG progress. (Ghaus, 2016). According to World Bank (2017), Pakistan's average statistical capacity score is $75.58 \%$ as compared to regional score of $74.87 \%$. The score is based on three key components, i.e. Methodology, source data and periodicity. (Khan \& Ali , 2019), initial assessment of data availability in Pakistan's context, portrays a dismal picture where data at the federal level on SDG 3 (good health and well-being), SDG 12 (responsible Consumption and production), SDG 14 (life below water), SDG 15 (life on land) and SDG16 (peace, justice and strong institutions) was lacking. Also, the gap widens from national to the district level. This assessment found that data indicators for SDGs 9 (industry, innovation and infrastructure), 10 (reduced Inequalities), 12 (responsible consumption and production) and 15 (life on land) are not available at district level. The main reason attributed to this gap is costs incurred and effort required to collect data at a disaggregated level

It provided an extensive overview of data sources available to track SDGs in Pakistan and highlighted the inability to capture quality of most indicators in terms of granularity (UNDP \& Pakistan Ministry of Planning, Development and Reform, 2018). Report on 'data gaps in Pakistan' aims to map existing sources of data on all SDGs through the TIER classification and then through Pakistan's own coding system developed that sub-categorises goals on basis of data regularity, standard availability and computation mechanism and level of effort. The mapping exercise revealed that almost 50 percent indicators have standards available and can be made available through minor efforts, however based on the coding system it was revealed that 28.9 percent of the indicators have standards but data is not available and major effort is required to collect data. Furthermore, goal-wise mapping revealed that 60 percent of data was available for goal 7 whereas 75 percent for goal 9, however the higher percentages hide inner discrepancies in terms of data accessibility and granularity

A similar scenario is echoed through the mapping analysis of Pakistan in the current study. The approach adapted is based on leveraging existing statistical capacity by adding more coherent data in the existing NSOs rather than developing new infrastructures for SDGs (Ariss \& Manley, 2018). Data disaggregation at sub-national levels mobilizes actions towards 'leaving no one behind'. In Pakistan, district-level analysis revealed a dismal picture, that of the 232 indicators only 30 were available on a regular basis whereas for 73 indicators new data was required and standards need to develop, timely data was not available for 14 indicators (UNDP \& Pakistan Ministry of Planning, Development and Reform, 2018).Such a finding would be impossible if data was, in fact, not disaggregated to the district level. If we want to take away the proverbial hammer from the policy makers, we need to first determine that the problems are heterogeneous as well.

The scope of the present study aims to be a crucial step towards SDG progress, monitoring and implementation in terms of measurement in Pakistan. There has been a lack of sufficient empirical work on measuring SDGs in Pakistan. The aim of the research is to map data sources in Pakistan in both local and international contexts. The mapping will provide a description of data availability, disaggregation level and reliability.

The initial mapping has been conducted for all 17 SDGs in Pakistan but the scope has been narrowed to two targets; Energy (Goal 7) and Infrastructure \& Industry (Goal 9) that are selected as a case study to propose a way forward. These two targets are mapped individually based on the four distinct dimensions of data availability, quality, granularity and accessibility. Data dissemination from national or provincial to district-level has been presented. Indicators classified as Tier 1 will be focused because of lack of standards available in Pakistan for Tier 2 and 3 indicators respectively (UNDP \& Pakistan Ministry of Planning, Development and Reform, 2018). This paper aims to employ existing statistical resources available and encapsulates the ability to enhance statistical capacity at the grass root level rather than mobilizing further resources in developing new surveys and engaging in traditional data collection processes. 


\section{METHODOLOGY \& DATA}

\section{Measuring SDGs in Pakistan}

This study follows a clear analytical framework for assessing data on the Sustainable Development Goals (SDGs) for Pakistan. First, a comprehensive mapping exercise was conducted which looked at national survey data, individual questions and identified corresponding SDGs and their respective targets. Survey years were chosen according to the latest available year prior to this study. Surveys included in this phase of the research were the Pakistan Social and Living Standards Measurement (PSLM) Survey 2014-15, the Multiple Indicator Cluster Survey (MICS) for 2017, the Pakistan Demographic and Health Survey (2017-18), the Labour Force Survey (2014-15), the Pakistan Economic Survey (2017-18), National Disaster Management Authority data, Police Department Data etc. When data was not locally documented, regional and international sources were consulted such as the World Development Indicators (World Bank), International Labor Organization, International Energy Agency etc.

Second, the data from the aforementioned sources was analysed under four dimensions, namely: data availability, quality, granularity and accessibility (shown in Table 1). This aided in specific analysis of the data landscape in light of the SDGs. It is well-documented in literature that disaggregated data helps in policy decision-making by highlighting specific stories that may otherwise be masked in aggregated summaries. Data granularity particularly at the district level is important in understanding not only national trends in SDG measurement, but also is crucial in highlighting the full spread of SDG performance. Moreover, for a country like Pakistan which has recently devolved numerous subjects from the federal to the provincial governments, such high granularity is a necessity if Pakistan stands a chance at attaining the SDGs.

TABLE 1

ASSESSMENT OF DATA POVERTY

\begin{tabular}{|l|l|}
\hline Dimension & Description \\
\hline Data Availability & Is the data available in a timely manner and documented in a measurable way? \\
\hline Data Quality & Is the data accurate, reliable and in a usable form? \\
\hline Granularity & Is the data available at all levels: national provincial and district levels? \\
\hline Accessibility & Is data accessible in the public domain? \\
\hline
\end{tabular}

The mapping exercise identified gaps under these dimensions. Furthermore, the IAEG-UN Tier Classification was consulted to identify Tier 1 Goals for Pakistan. According to this Tier Classification Criteria: "Tier 1: Indicator is conceptually clear, has an internationally established methodology and standards are available, and data are regularly produced by countries for at least 50 per cent of countries and of the population in every region where the indicator is relevant (United Nations Statistical Division, 2018). Goals 7 and 9 were selected as case study Tier 1 goals which had partial or missing data for Pakistan. These were subjected to the mapping exercise, as shown in Table 2. This process helped identify the actual evidence needed to measure specific SDGs for Pakistan's context. Through this process, SDG 7 and 9 were studied in depth according to goals and specific targets, the four dimensions (availability, quality, granularity and accessibility), and whether there was a standard available or not.

The Pakistan Energy Yearbook (2018) was consulted as the primary national data source available for Goal 7. Electricity Consumed by Agriculture and Industrial Sector district-wise (2014-15) was used respectively. The Services sector was omitted due to lack of data available on national figures for energy consumption in the Pakistan Energy Yearbook 2018. To calculate the value of economic output, provincial Gross Domestic Product (GDP) at the provincial level was used for 2014-15 as documented by 
the Punjab Economic Research Institute (PERI). Furthermore, PSLM 2014-15 data was used for the following:

- Total Observations for each province

- Total population of each district

- Total employed in each district

- Employed in each of three sectors; Agriculture, Industry \& Services

In this section we layout the sources of data used to aid our analysis. The purpose of this paper is to disaggregate each tier 1 sub-indicator of Goal 7 and Goal 9 to the district level. The rationale for this is that following the Eighteenth Amendment to Pakistan's Constitution, a substantial number of subjects were devolved from the deferral to the provincial level (National Assembly Pakistan, 2010). Now, while the signatory to the SDG Agenda is the Federal government, it is not plausible for Pakistan to achieve the SDG targets without the cooperation of the provinces. Within Pakistan, the performance of the provinces varies in terms of governance and delivery of public good and services. By disaggregating each indicator and its measurement down to the district level, the authors hope to assist provincial and federal government in monitoring, measurement, evaluation and attainment of the SDGs.

The focus of this paper is the seventh and ninth SDG. We will, in turn, look at Tier I indicators for each goal. For each indicator and sub-indicator, we propose a way forward given Pakistan's existing and fairly extensive data collection. Section 2.1 focuses of SDG 7 and section 2.2 focuses on SDG 9 .

\section{Measuring SDG 7}

The seventh SDG promises access to affordable, reliable, sustainable, clean and modern energy for everyone. It is broken down into 5 sub-indicators: 7.1, 7.2, 7.3, 7.a, and 7.b. In analysing SDG 7, individual targets were mapped according to their Tier Classification and Tier I targets were selected for the study. These included SDG targets 7.1.1, 7.1.2, 7.2.1 and 7.3.1. The international mapping source was identified, local mapping source and specific survey questions where this information was available. The granularity at the district level aided analysis. It is also pertinent to measure that progress of this SDG is tracked and presented in The Energy Progress Report [Sustainable Energy for All (SE4All)]. We will now look at Tier I targets under the seventh SDG in turn.

\section{Indicator 7.1}

Goal 7.1 asserts "By 2030, ensure universal access to affordable, reliable and modern energy services". To measure this sub-indicator, the UNDP proposes two sub-sub indicators, 7.1.1 and 7.1.2. Both are Tier I indicators.

\section{Sub-sub Indicator 7.1.1}

This indicator reads as "Percentage of population with access to electricity". To measure this, we use data from Pakistan Demographic Health Survey 2017 question number 121. This question asks, "Does your household have electricity?" This data is available at the district level in Pakistan.

\section{Sub-sub Indicator 7.1.2}

This indicator reads as "Proportion of population with primary reliance on clean fuels and technology".

This is defined as "the number of people using clean fuels and technologies for domestic cooking, heating and lighting divided by total population reporting any cooking, heating or lighting. It is expressed as a percentage".(United Nations Statistics Division, 2018) It is pertinent, for the sake of clarity, to define clean fuel and technologies as well.

Clean fuel and technologies is defined by the emission rate targets and specific fuel recommendations that are contained in the 'Guidelines for Indoor Air Quality: Household Fuel Combustion' report by the World Health Organization (WHO).

Now, we look at question number 113 from PDHS 2017-18 which specifically asks, "What type of fuel does your household mainly use for cooking?" To calculate the proportion of population with primary 
reliance on clean fuel $\alpha_{i}$, we divide the population (in each district) that uses any clean fuel, $a_{i, c}$ by the total population (in respective district) that uses any (clean and/or dirty) cooking fuel, $a_{i, e}$ where $e=c+$ $d$. Clean source is represented by $c$ while dirty source is represented by $d$. Clean fuels included in calculations are Biogas, Natural Gas, Electricity and LPG.

Formally we say in

$\frac{a_{i, c}}{a_{i, e}}=\alpha_{i}$

\section{Indicator 7.2}

This indicator aims that "By 2030, increase substantially the share of renewable energy in the global energy mix". To measure this sub-indicator, the UNDP proposes a sub-sub indicator, 7.2.1 which is a Tier I indicator.

\section{Sub-sub Indicator 7.2.1}

This indicator reads as "Renewable energy's share in the total final energy consumption". The data for this is available in the Energy Yearbook. Data for total final energy consumption in Pakistan is available and so is the total share of renewable energy.

To measure this, we need to divide the final energy consumption from all renewables by total final energy consumption across the country. Pakistan's data reports total final energy consumption disaggregated in five categories - oil, gas, coal, electricity and LPG. Data for this is measured in Tonnes of Oil Equivalent (ToE). According to UN Statistics Division's official classification, "Renewable energy consumption includes consumption of energy derived from: hydro, solid biofuels, wind, solar, liquid biofuels, and biogas, geothermal, marine and waste. Total final energy consumption is calculated from national balances and statistics as total final consumption minus non-energy use" (United Nations Statistics Division, 2018).

In this section we will bring to light existing data on energy consumption and propose methods of collecting data in line with the United Nation's International Recommendations for Energy Statistics (IRES) (United Nations DESA, 2018) recommended disaggregation.

Pakistan's Energy Yearbook (Table 1.1 on p.3) provides a plethora of information on the country's electricity generation. It is disaggregated along four sources: Renewable, Hydro, Nuclear and Imported. It is recommended that renewable electricity's share in electricity generation be disaggregated along the eight categories/sources recommended by (United Nations DESA, 2018) in the Pakistan Energy Yearbook. While this indicator does not concern itself with generation, it would be worthwhile to collect disaggregated data on electricity generation as well to understand the impediments to the adoption of renewable energy in consumption.

\section{Indicator 7.3}

Goal 7.3 aims to "Double the global rate of improvement in energy efficiency by 2030". To measure this sub-indicator, the UNDP proposes one sub-sub indicator, 7.3.1 which is a Tier I indicator.

\section{Sub-sub Indicator 7.3.1}

Energy intensity is defined as the energy supplied to the economy per unit value of economic output. (United Nations Statistics Division, 2018). To calculate the energy intensity, we have to divide the energy supplied to a sector in a district by the GDP of that sector in that district. Different disaggregation methods are suggested for this indicator. Using Pakistan's data, we propose to estimate the energy intensity of Industry and Agriculture sector across all districts of the country.

To do this we use population and employment data from PSLM. The provincial GDP values that we will disaggregate to the district level come from Punjab Economic Research Institute based in Lahore, Pakistan. 
We begin by determining the share of a district in the provincial GDP, denoted by $\mathrm{d}_{\mathrm{i}, \mathrm{h}}$, by taking the product of the provincial GDP with the district's population $\left(\mathrm{a}_{\mathrm{i}}\right)$ and dividing this by the total population in the province $\left(\pi_{\mathrm{h}}\right)$.To calculate the industrial sector's share in the district's GDP $\left(\mathrm{e}_{\mathrm{i}, \mathrm{h}}\right)$, we take the product of $\mathrm{d}_{\mathrm{i}, \mathrm{h}}$ and total persons employed in the industrial sector in the district $\left(\mathrm{c}_{\mathrm{i}, \mathrm{h}}\right)$. This is divided by total persons employed in the district $\left(\gamma_{\mathrm{i}, \mathrm{h}}\right)$. This gives us a PKR value for the industrial sector's share in the district's GDP. This calculation is done for all districts of each province. So, as Punjab has 36 district, we get 36 values for e. The sum of these gives the provincial e ( $e_{\text {Punjab }}$ ). Each district's $e$ is normalized by the provincial e to give each district's weight, $\mathrm{f}_{\mathrm{i}, \mathrm{h}}$. Each respective $\mathrm{f}$ is multiplied with Total Electricity Consumed by the Industry sector at the national (A) level to determine each district's share in total electricity consumed $\left(\mathrm{g}_{\mathrm{i}, \mathrm{h}}\right)$, where the sum of all $\mathrm{g}$ must equal A. Now as a final step, to calculate energy intensity we will divide the energy supplied to industrial/agricultural sector in a given district by the GDP of the industrial/agricultural sector in that district. Since Pakistan does not collect details on energy supplied beyond the decomposition by source, and that too is available only as an aggregated national level figure, this methodology aims to suggest a way forward to improve data collection for this subindicator. For all equations, $\mathrm{h}=1,2,3,4 . \mathrm{p}=1$ refers to Punjab, 2 refers to Sindh, 3 refers to KPK and 4 refers to Baluchistan. $i$ refers to each unique district in a province.

$\frac{a_{i}}{\pi_{h}} \times G D P_{h}=d_{\mathrm{i}, \mathrm{h}}$

\section{Measuring SDG 9}

The ninth SDG focuses on infrastructure development which is conducive to human development, sustainable and inclusive industrialization and higher levels of innovation across the world. It is broken down into 8 sub-indicators: 9.1, 9.2, 9.3, 9.4, 9.5, 9.a, 9.b, and 9.c. In analysing SDG 9, individual targets were mapped according to their Tier Classification and Tier I targets were selected for the study. These included SDG targets 9.1.2, 9.2.1, 9.2.2, 9.4.1, 9.5.1, 9.5.2, 9.a.1, 9.b.1 and 9.c.1. The international mapping source was identified, local mapping source and specific survey questions where this information was available. The granularity at the district level aided analysis. At the time of writing, we have completed our analysis for four tier 1 indicators. The following subsections look at tier I indicators of goal 9 for Pakistan.

\section{Indicator 9.2}

Goal 9.2 aims to "[P]romote inclusive and sustainable industrialization and, by 2030, significantly raise industry's share of employment and gross domestic product, in line with national circumstances, and double its share in least developed countries". To measure this sub-indicator, the UNDP proposes two sub-sub indicators, 9.2.1 and 9.2.2. Both are Tier I indicators.

\section{Sub-sub Indicator 9.2.1}

This indicator reads as "Manufacturing value added as a proportion of GDP and per capita". To measure this, we use data from PSLM 2014-15.

\section{Sub-sub Indicator 9.2.2}

This indicator aims to determine Manufacturing employment as a proportion of total employment. Findings for this indicator stem from the PSLM 2014-15 using Pakistan's Occupation Codes.

\section{Indicator 9.5}

Goal 9.5 aims to "[E]nhance scientific research, upgrade the technological capabilities of industrial sectors in all countries, in particular developing countries, including, by 2030, encouraging innovation and substantially increasing the number of research and development workers per 1 million people and public and private research and development spending." To measure this sub-indicator, the UNDP proposes two sub-sub indicators, 9.5.1 and 9.5.2. Both are Tier I indicators. 


\section{Sub-sub Indicator 9.5.1}

This indicator reads as "Research and development expenditure as a proportion of GDP". The current draft does not cover this sub-sub indicator.

\section{Sub-sub Indicator 9.5.2}

This indicator reads as "Researchers (in full-time equivalent) per million inhabitants". Findings for this indicator stem from the PSLM 2014-15 using Pakistan's Occupation Codes.

\section{Indicator 9.6}

Goal 9.b focuses on "Support(ing) domestic technology development, research and innovation in developing countries, including by ensuring a conducive policy environment for, inter alia, industrial diversification and value addition to commodities". To measure this sub-indicator, one Tier I sub-sub indicator, 9.c.1, is proposed.

\section{Sub-sub Indicator 9.b.1}

This indicator reads as "Proportion of medium and high-tech industry value added in total value added".

\section{Indicator 9.c}

Goal 9.c aims to "[S]ignificantly increase access to information and communications technology and strive to provide universal and affordable access to the Internet in least developed countries by 2020". To measure this sub-indicator, the UNDP proposes one sub-sub indicator, 9.c. 1 which is a Tier I indicator.

\section{Sub-sub Indicator 9.c.1}

This indicator reads as "Proportion of population covered by a mobile network, by technology". To measure this sub-sub indicator, we use data from PSLM 2014-15.

\section{FINDINGS}

Section 3 presents the findings on measuring SDGs in Pakistan in the light of SDG 7 and SDG 9, tier 1 goals where data granularity presented the biggest challenge in accurate measurement of the goals. We looked at specific indicators that fall under Tier I where data was still found missing in the Pakistani context, namely under SDG 7 and 9. Through this exercise, we drew implications for a structured and coherent data collection process for SDGs in Pakistan. Our study finds that 9 SDG Targets and their indicators have missing or partial data available. It makes policy recommendations on specific indicators that fall under Tier I where data was still found missing in the Pakistani context, namely under SDG 7 and 9. Moreover, recommendations were made on a collation of disparate sets of data under a proposed SDG data system.

\section{Findings for SDG 7}

While on the national level, estimates may be made in sub-indicators 7.1, 7.2 and 7.3, a lack of availability of data at the provincial and more so at the district level meant that measurement of SDG may not be possible at a disaggregated level. Based on the methodology in section 3, this section describes our findings from the first phase of our study on data mapping of SDGs in Pakistan, and then follows with specific findings on each of the sub-indicators of goal 7.

\section{Findings for Indicator 7.1}

In this subsection we will present findings of Tier I sub-sub indicators, namely 7.1.1 and 7.1.2. 
Findings for Indicator 7.1.1

For this sub-sub indicator, we used data from PDHS 2017. Table 3 presents our findings for a few districts from across Pakistan. Complete set of findings can be shared upon request. We used data pertaining to question number 121. The choice of districts is such that each district represents a geographical division of the province. Attock represents northern Punjab, Bahawalpur represents Southern Punjab while Lahore represents central Punjab. The same applies to the other three provinces.

TABLE 2

FINDINGS FOR 7.1.1

\begin{tabular}{|c|c|c|c|c|}
\hline \begin{tabular}{|l} 
Province \\
$(1)$
\end{tabular} & \begin{tabular}{|l} 
District \\
$(2)$
\end{tabular} & $\begin{array}{l}\text { Electricity } \\
\text { (Yes) } \\
(3) \\
\end{array}$ & $\begin{array}{l}\text { Total population } \\
\text { in district } \\
(4)\end{array}$ & $\begin{array}{l}\text { Proportion of population with } \\
\text { access to electricity } \\
(5)(3 / 4)(\%) \\
\end{array}$ \\
\hline \multirow[b]{3}{*}{ Punjab } & Attock & 69 & 80 & 86.25 \\
\hline & Bahawalpur & 126 & 132 & 95.45 \\
\hline & Lahore & 343 & 344 & 99.71 \\
\hline \multirow[b]{7}{*}{ Sindh } & Badin & 54 & 80 & 67.50 \\
\hline & Karachi Central & 260 & 260 & 100 \\
\hline & Karachi East & 200 & 203 & 98.52 \\
\hline & Karachi Malir & 123 & 123 & 100 \\
\hline & Karachi South & 139 & 139 & 100 \\
\hline & Karachi West & 232 & 232 & 100 \\
\hline & Sukkur & 49 & 76 & 64.47 \\
\hline \multirow[b]{3}{*}{ KPK } & Abbottabad & 98 & 98 & 100 \\
\hline & Nowshera & 138 & 138 & 100 \\
\hline & Peshawar & 418 & 429 & 97.43 \\
\hline \multirow[b]{3}{*}{ Balochistan } & Gwadar & 53 & 76 & 69.73 \\
\hline & Quetta & 230 & 232 & 99.14 \\
\hline & Sibi & 22 & 22 & 100 \\
\hline
\end{tabular}

As can be seen that Punjab performs relatively well in this sub-sub indicator. Sindh's performance is more varied, with Karachi outshining the other relatively impoverished districts of the province. It is worth pointing out that Karachi is Pakistan's largest city in terms of population, it is also a port city which makes it a hub for trade as well. It hosts a plethora of industries in Pakistan. Like Punjab, KPK also performs well. While in Baluchistan, the provincial capital, Quetta, performs well, Gwadar which is from the south of the province performs abysmally.

\section{Findings for Indicator 7.1.2}

For this sub-sub indicator, we used data from PDHS 2017. Table 4 presents our findings for a few districts from across Pakistan. We used data pertaining to question number 113. 
As can be seen that Punjab performs poorly in this sub-sub indicator. The only exception is the provincial capital, Lahore. Sindh's performance is similar to Punjab, although its peripheral districts perform better than Punjab's. KPK performs well and actually much better than Punjab and Sindh. While in Baluchistan, the provincial capital, Quetta, performs well, Gwadar again poses some deep concerns.

TABLE 3

FINDINGS FOR 7.1.2

\begin{tabular}{|c|c|c|c|c|}
\hline $\begin{array}{l}\text { Province } \\
\text { (1) }\end{array}$ & $\begin{array}{l}\text { Districts } \\
\text { (2) }\end{array}$ & $\begin{array}{l}\text { Clean } \\
\text { Fuels } \\
(3)\end{array}$ & $\begin{array}{l}\text { All } \\
\text { fuels } \\
(4)\end{array}$ & $\begin{array}{l}\text { Proportion } \\
\text { with reliance } \\
\text { on clean fuels } \\
\text { (5) }(3 / 4)(\%)\end{array}$ \\
\hline \multirow{3}{*}{ Punjab } & Attock & 6 & 80 & 7.5 \\
\hline & Bahawalpur & 49 & 132 & 37.12 \\
\hline & Lahore & 324 & 344 & 94.19 \\
\hline \multirow{7}{*}{ Sindh } & Badin & 22 & 80 & 27.5 \\
\hline & Sukkur & 49 & 76 & 63.16 \\
\hline & Karachi Central & 257 & 260 & 98.85 \\
\hline & Karachi East & 204 & 204 & 100 \\
\hline & Karachi Malir & 117 & 123 & 95.12 \\
\hline & Karachi South & 137 & 139 & 98.56 \\
\hline & Karachi West & 228 & 232 & 98.27 \\
\hline \multirow{3}{*}{ KPK } & Abbottabad & 52 & 98 & 53.06 \\
\hline & Nowshera & 126 & 138 & 91.3 \\
\hline & Peshawar & 368 & 429 & 85.78 \\
\hline \multirow{3}{*}{ Baluchistan } & Sibbi & 18 & 22 & 81.81 \\
\hline & Gwadar & 14 & 76 & 18.42 \\
\hline & Quetta & 231 & 232 & 99.57 \\
\hline
\end{tabular}


FIGURE 1

PROPORTION OF POPULATION WITH RELIANCE ON CLEAN FUELS

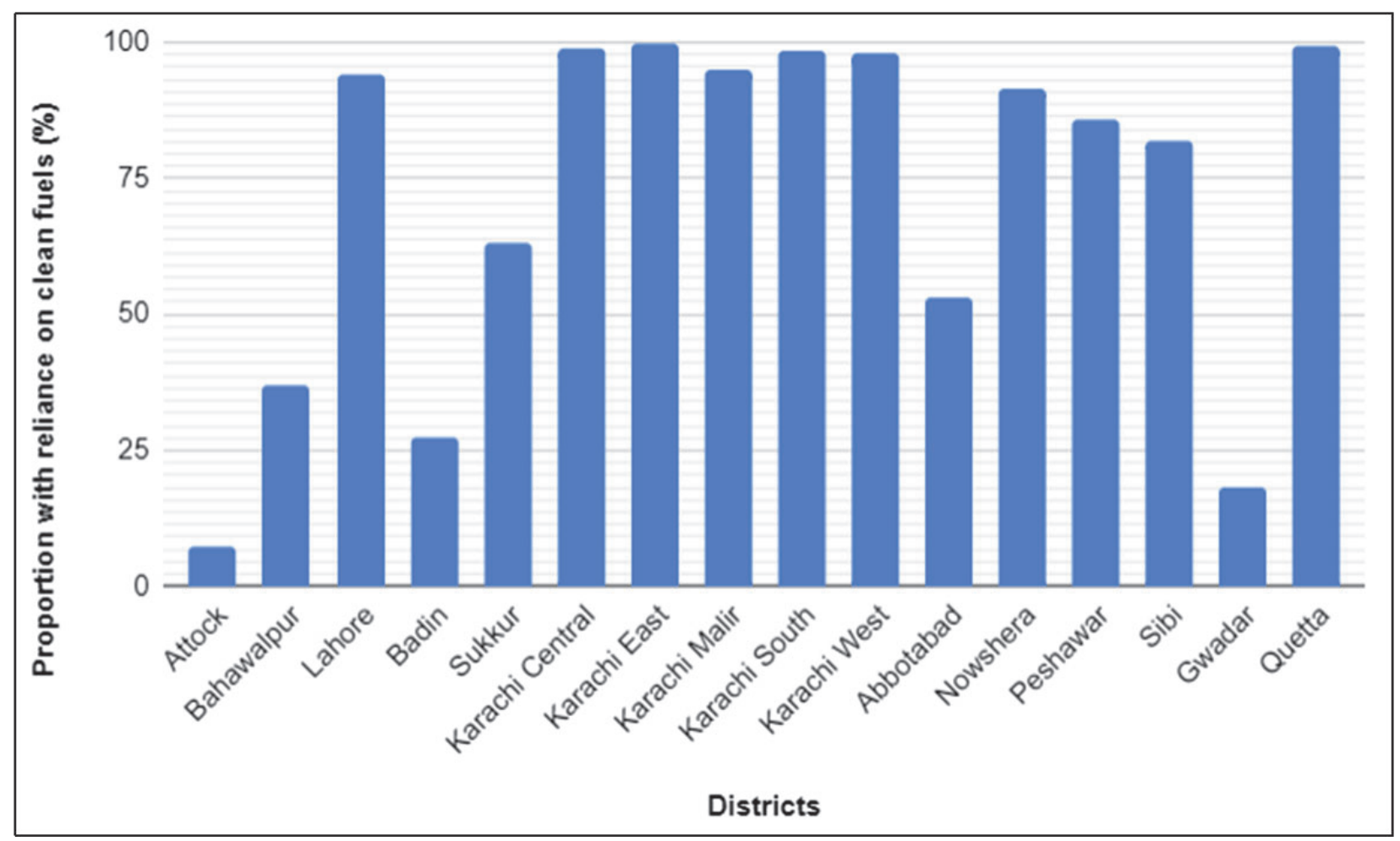

Findings for Indicator 7.2

Findings for Sub-Sub Indicator 7.2.1.

On the sectorial side, the Pakistan Energy Yearbook collects and provides data on Energy Consumption in major sectors like Industry and Agriculture. This is further disaggregated by source: LPG, Gas, Electricity and Coal.

We propose splitting Electricity in two groups - renewable and non-renewable. Within renewable, disaggregation should be done along the eight categories recommended by (United Nations DESA, 2018).

A very interesting extension and use of this indicator is at the household level. We recommend adding and extending existing questions in PDHS and PSLM. The rationale for adding questions related to renewable energy consumption is not only the estimation of this indicator but also to study household behaviour and choice in energy composition. This will also help calibrate a national energy policy.

The following question can be included in PDHS as Q.122 under Household Characteristics. The current Q. 121 asks whether the household has electricity. Our suggested question reads as follows:

"Did this household install/consume

1. Wind

2. Solar

3. Biogas

4. Solid biofuel (fuel-wood, animal waste, vegetable waste, black liquor, bagasse, charcoal)"

In Section G of the PSLM survey, question number 8 asks about the source of light in the household. One of the categories here is firewood which can be used as a proxy for solid biofuels. We suggest adding additional categories in this questions, e.g., wind and solar. This will help us study the consumption of 
renewable energy at the household level without substantially affecting the burden of the questionnaire. These findings point towards implications for a structured and coherent data collection process for SDGs in Pakistan.

\section{Findings for Indicator 7.3}

\section{Findings for Indicator 7.3.1}

Data is only available at the national level at the time of the writing of this paper and there is no existing disaggregation on a subnational level. The data on the national level is currently collated under the Sustainable Energy for All (SE4All) database measured in the units MJ/\$2011 PPP GDP (World Bank, IEA \& ESMAP, 2019).

\section{Findings for SDG 9}

This section presents the findings for SDG 9, based on the methodology of section 2. It describes specific findings for each of the tier I indicators of SDG 9 for Pakistan. It focuses on Indicator 9.2, subsub indicators 9.2.1 and 9.2.2, Indicator 9.5, sub-indicator 9.5.2, Indicator 9.c and sub-indicator 9.c.1.

\section{Findings for Indicator 9.2}

In this subsection we will present findings of Tier I sub-sub indicators, namely 9.2.1 and 9.2.2.

\section{Findings for Indicator 9.2.1}

This sub-sub indicator is measured by first calculating GDPs for all districts in each of the four provinces. This is done by dividing each district's population by that of the province it belongs to. This gives us a distinct weight for each district. This is multiplied with the provincial GDP to give each district's respective GDP. The next step is to disaggregate the district's sector-wise GDP, specifically for manufacturing sector. This is done by looking at the proportion of the population (in the district) employed in manufacturing. These manufacturing codes were obtained from Industry Occupation Classification (PSLM 2014-15 Microdata) to calculate employed in manufacturing. We normalize this by total persons employed in the district. The district wise GDP is then weight adjusted sector-wise. Below, in Table 5 we present provincial populations and GDPs. Table 6 reports our findings for selected districts.

TABLE 4

\section{AUTHOR'S COLLATION FROM SOURCES PSLM 2014-15 \& PERI}

\begin{tabular}{|l|l|l|}
\hline Province & Population (PSLM 2014-15 & GDP (PKR) \\
\hline Punjab & 226179 & 5771317.544 \\
\hline Sindh & 119395 & 3152458 \\
\hline KPK & 95272 & 1220902.744 \\
\hline Baluchistan & 73099 & 487045 \\
\hline
\end{tabular}


TABLE 5

DISTRICT-WISE EMPLOYMENT IN MANUFACTURING

\begin{tabular}{|l|l|l|l|l|l|l|l|}
\hline \multirow{3}{*}{$\begin{array}{l}\text { Province } \\
\text { (1) }\end{array}$} & District & $\begin{array}{l}\text { Manufacturing } \\
\text { employed (2) }\end{array}$ & $\begin{array}{l}\text { All } \\
\text { Employed }\end{array}$ & $\begin{array}{l}\text { Total } \\
\text { Employed } \\
\text { Population } \\
\text { (3) }\end{array}$ & $\begin{array}{l}\text { District } \\
\text { Population } \\
\text { (4) }\end{array}$ & $\begin{array}{l}\text { GDP } \\
\text { District- } \\
\text { wise } \\
\text { (PKR) (5) }\end{array}$ & $\begin{array}{l}\text { Manufacturing } \\
\text { share in } \\
\text { District GDP } \\
\text { (6) }\end{array}$ \\
\hline \multirow{4}{*}{ Punjab } & Attock & 66 & 1144 & 1210 & 4520 & 115335.00 & 6291 \\
\cline { 2 - 8 } & Bahawalpur & 414 & 4366 & 4780 & 11900 & 303647.46 & 26299 \\
\cline { 2 - 8 } & Lahore & 270 & 745 & 1015 & 3441 & 87802.60 & 23356 \\
\hline \multirow{5}{*}{ Sindh } & Badin & 150 & 2477 & 2627 & 7628 & 201406.67 & 11500 \\
\cline { 2 - 8 } & Sukkur & 99 & 998 & 1097 & 3976 & 104980.72 & 9474 \\
\cline { 2 - 8 } & Karachi & 245 & 636 & 881 & 3104 & 81956.78 & 22792 \\
\hline \multirow{3}{*}{ KPK } & Abbottabad & 26 & 440 & 466 & 2389 & 30614.84 & 1708 \\
\cline { 2 - 8 } & Nowshera & 63 & 562 & 625 & 3016 & 38649.79 & 3896 \\
\cline { 2 - 8 } & Peshawar & 76 & 594 & 670 & 3195 & 40943.66 & 4644 \\
\hline \multirow{3}{*}{ Balochistan } & Sibbi & 16 & 502 & 518 & 1967 & 13105.75 & 405 \\
\cline { 2 - 8 } & Gwadar & 18 & 303 & 321 & 1790 & 11926.44 & 669 \\
\cline { 2 - 8 } & Quetta & 34 & 451 & 485 & 2245 & 14958.02 & 1049 \\
\hline
\end{tabular}

Findings for Indicator 9.2.2

This sub-sub indicator is measured by aggregating manufacturing-related Industry codes in PSLM 2014-15. These are all codes under Section C (Manufacturing). District specific data is presented in column 3 of Table 7 Specifically, we focused on question 5 (Employment section Part A) to estimate this sub-sub indicator. The question reads as follows, "What was the nature of work done by the enterprise, office, Institution?

Findings of this sub-sub indicator are presented in column 5. Our findings show that the proportion of population employed in manufacturing is very low, across provinces. 
TABLE 6

DISTRICT-WISE PROPORTION OF POPULATION EMPLOYED IN MANUFACTURING SECTOR

\begin{tabular}{|l|l|l|l|l|}
\hline $\begin{array}{l}\text { Province } \\
(\mathbf{1})\end{array}$ & $\begin{array}{l}\text { Districts } \\
\mathbf{( 2 )}\end{array}$ & $\begin{array}{l}\text { Employed in } \\
\text { manufacturing (3) }\end{array}$ & $\begin{array}{l}\text { Total } \\
\text { Employed (4) }\end{array}$ & $\begin{array}{l}\text { Proportion Employed } \\
\text { in Manufacturing (5) } \\
(\mathbf{3} / \mathbf{4})\end{array}$ \\
\hline \multirow{4}{*}{ Punjab } & Attock & 66 & 1,210 & 5.45 \\
\cline { 2 - 5 } & Bahawalpur & 414 & 4,780 & 8.66 \\
\cline { 2 - 5 } & Lahore & 270 & 1,015 & 26.60 \\
\hline \multirow{4}{*}{ Sindh } & Badin & 150 & 2,627 & 5.71 \\
\cline { 2 - 5 } & Sukkur & 99 & 1,097 & 9.02 \\
\cline { 2 - 5 } & Karachi & 245 & 881 & 27.81 \\
\hline \multirow{3}{*}{ KPK } & Abbottabad & 26 & 466 & 5.58 \\
\cline { 2 - 5 } & Nowshera & 63 & 625 & 10.08 \\
\cline { 2 - 5 } & Peshawar & 76 & 670 & 11.34 \\
\hline \multirow{3}{*}{ Balochistan } & Sibbi & 16 & 518 & 3.09 \\
\cline { 2 - 5 } & Gwadar & 18 & 321 & 5.61 \\
\cline { 2 - 5 } & Quetta & 34 & 485 & 7.01 \\
\hline
\end{tabular}

Findings for Indicator 9.5

In this subsection we will present findings of Tier I sub-sub indicator 9.5.2.

Findings for Indicator 9.5.2

This sub-sub indicator is measured by analysing one R\&D related employment code in PSLM 201415. The unique identifier code for Research \& Development Managers is 1223.

District specific data is presented in column 3 of Table 8 Specifically, we focused on question four of section $\mathrm{G}$ (Detail of the Family) to estimate this sub-sub indicator. Findings of this sub-sub indicator are presented in column 3.

TABLE 7

RESEARCHERS (IN FULL-TIME EQUIVALENT) PER MILLION INHABITANTS

\begin{tabular}{|l|l|l|}
\hline $\begin{array}{l}\text { Province } \\
\text { (1) }\end{array}$ & $\begin{array}{l}\text { District } \\
\mathbf{( 2 )}\end{array}$ & $\begin{array}{l}\text { R\&D Managers } \\
\mathbf{( 3 )}\end{array}$ \\
\hline \multirow{2}{*}{ KPK } & Mardan & 2 \\
\cline { 2 - 3 } & Peshawar & 1 \\
\hline \multirow{3}{*}{ Punjab } & Rawalpindi & 1 \\
\cline { 2 - 3 } & Faisalabad & 1 \\
\cline { 2 - 3 } & Lahore & 1 \\
\hline Sindh & Hyderabad & 1 \\
\hline
\end{tabular}


Findings for Indicator 9.b

In this subsection we will present findings of Tier I sub-sub indicator 9.b.1, which looks at the proportion of medium and high-tech industry value added in total value added.

Findings for Indicator 9.b.1

There is no directly identifiable source for estimation of the sub-sub indicator 9.b.1. So we took a two-pronged approach. We have looked at publicly and privately owned firms that belong to the medium and high tech industry. Here we will explain each in turn. For privately owned firms, we accessed data provided by the (World Bank, 2019). The survey provides data for 1247 firms. The Survey has a follow up module called the Innovation Module as well which 696 firms have responded to. Based on the International Standard Industrial Classification of All Economic Activities, we identified medium and high-tech firms. Based on that, we filtered the firms from the Survey that fell under those categories. Based on SDGs definition the following four digit codes were used to extract medium and high-tech industries in the manufacturing sector as represented in table 8 below:

TABLE 8

ISIC DESCRIPTION BASED ON SDG 9 CRITERIA

\begin{tabular}{|l|l|l|}
\hline ISIC Revision 3 & $\begin{array}{l}\text { 4-digit } \\
\text { classification }\end{array}$ & Description \\
\hline 24 & $2411-2430$ & Manufacture of chemicals and chemical products \\
\hline 29 & $2911-2930$ & Manufacture of machinery and equipment \\
\hline 30 & 3000 & Manufacture of office, accounting and computing machinery \\
\hline 31 & $3110-3190$ & Manufacture of electrical machinery and apparatus n.e.c \\
\hline 32 & $3210-3230$ & $\begin{array}{l}\text { Manufacture of radio, television and communication equipment } \\
\text { and apparatus }\end{array}$ \\
\hline 33 & $3311-3330$ & $\begin{array}{l}\text { Manufacture of medical, precision and optical instruments, } \\
\text { watches and clocks }\end{array}$ \\
\hline 34 & $3410-3430$ & Manufacture of motor vehicles, trailers and semi-trailers \\
\hline 35 & $3511-3599$ & Manufacture of other equipment \\
\hline
\end{tabular}

Source: United Nations Statistics Division, 2019 (https://unstats.un.org/sdgs/metadata/files/Metadata-09-0B-01.pdf)

Below we present the proportion of medium and high tech firms in Pakistan's private sector as per the Survey. We present the number of firms present in each category with respect to the size of the firm. So, there are thirty-nine small, forty-six medium, and twenty large sized firms in the chemical manufacturing category.

Our findings suggest that in Pakistan's private sector, a little over seventeen percent of the firms belong to the medium and high tech sector. Of these, thirty-six percent are small firms, thirty-seven percent are medium size and only twenty percent are large sized firms (See Table 9 below). 
TABLE 9

ENTERPRISE SURVEY DATA AND FIRM CLASSIFICATION

\begin{tabular}{|c|c|c|c|c|c|c|c|c|c|c|c|}
\hline \begin{tabular}{|l} 
Firm Size \\
\end{tabular} & $\begin{array}{l}24 \\
(1)\end{array}$ & $\begin{array}{l}29 \\
(2)\end{array}$ & $\begin{array}{l}30 \\
(3)\end{array}$ & $\begin{array}{l}31 \\
(4)\end{array}$ & $\begin{array}{l}32 \\
(5)\end{array}$ & $\begin{array}{l}33 \\
(6)\end{array}$ & $\begin{array}{l}34 \\
(7)\end{array}$ & $\begin{array}{l}35 \\
(8)\end{array}$ & $\begin{array}{l}\text { Sum of MHT } \\
\text { firms } \\
(9) \\
(1+2+\ldots+8)\end{array}$ & $\begin{array}{l}\text { Sum of all } \\
\text { firms } \\
(10)\end{array}$ & $\begin{array}{l}\text { Proportion of } \\
\text { MHT in total } \\
\text { firms }(\%) \\
(11) \\
(9 / 10)\end{array}$ \\
\hline $\begin{array}{l}\text { Small (5-19 } \\
\text { employees) }\end{array}$ & 39 & 15 & 1 & 8 & 1 & 8 & 5 & 1 & 78 & 496 & 15.73 \\
\hline $\begin{array}{l}\text { Medium (20-99 } \\
\text { employees) }\end{array}$ & 46 & 14 & 0 & 7 & 1 & 6 & 7 & 1 & 82 & 361 & 22.71 \\
\hline $\begin{array}{l}\text { Large (+ } 100 \\
\text { employees) }\end{array}$ & 20 & 5 & 0 & 3 & 1 & 8 & 6 & 2 & 45 & 170 & 26.47 \\
\hline N.E.C. & 6 & 1 & 0 & 0 & 0 & 0 & 6 & 1 & 14 & 220 & 6.36 \\
\hline Total & 111 & 35 & 1 & 18 & 3 & 22 & 24 & 5 & 219 & 1247 & 17.56 \\
\hline
\end{tabular}

Source: World Bank Enterprise Survey - Pakistan 2013. Authors' calculation

For publicly owned firms, we looked at publicly listed firms that were categorized as medium and high tech. Data for these firms were accessed from Pakistan Stock Exchange. Out of 431 firms listed, 121 met the criteria as per SDG definitions. To ensure that firms were correctly mapped on to the SDGs conceptual framework all firms were mapped for meeting the four-digit criteria of ISIC revision 3. To calculate value addition, we looked at each company's shares with respect to total shares in the Exchange (as of November $19^{\text {th }} 2019$ ). Some of our findings are reported below in Table 10: 


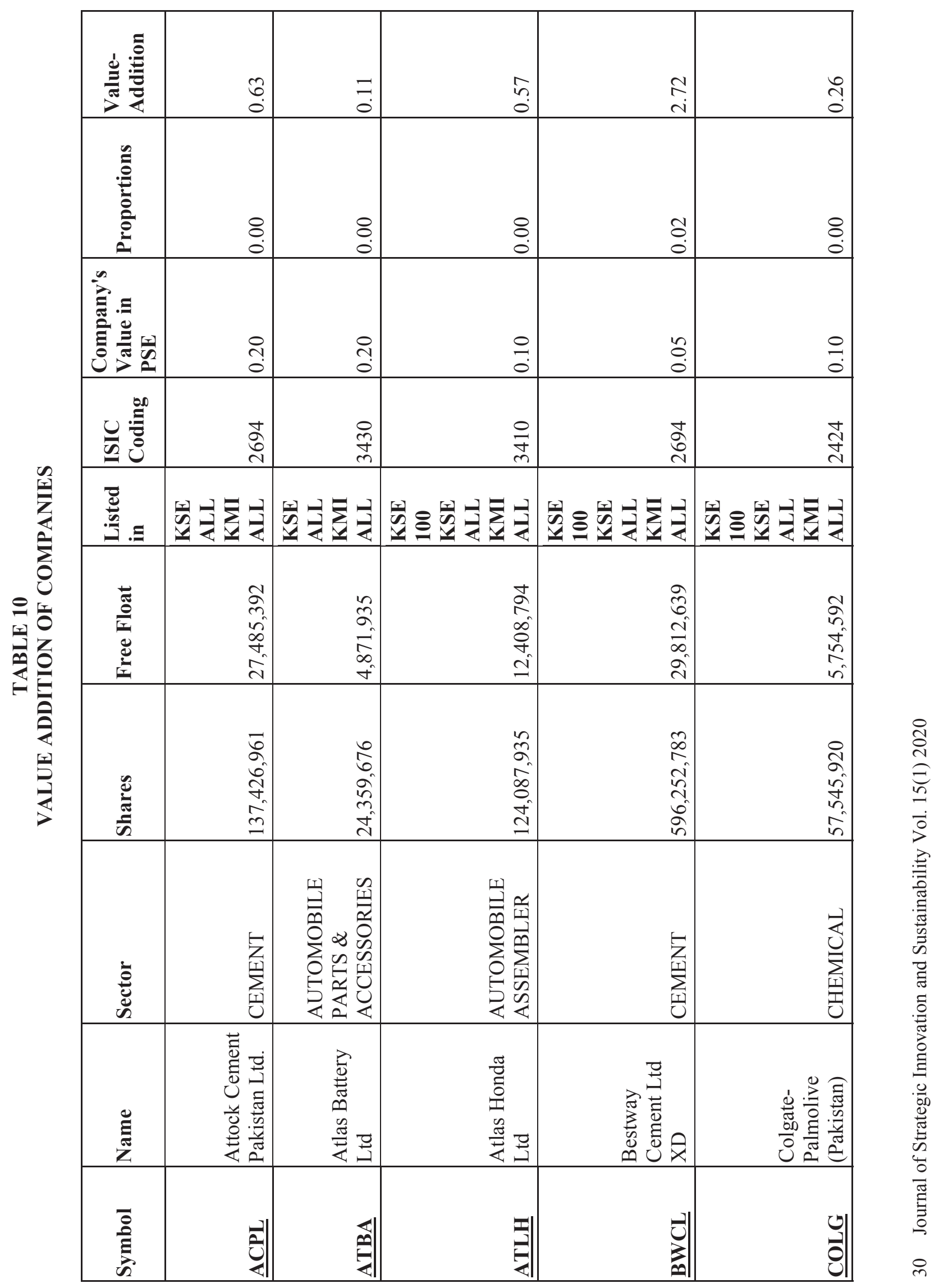




\begin{tabular}{|c|c|c|c|c|}
\hline 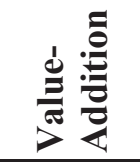 & in & के & 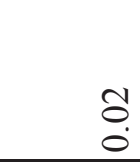 & \pm \\
\hline 产 & $\stackrel{8}{\circ}$ & $\begin{array}{l}8 \\
:\end{array}$ & $\stackrel{8}{\circ}$ & $\begin{array}{l}8 \\
0 \\
0\end{array}$ \\
\hline 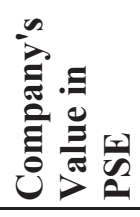 & $\stackrel{n}{0}$ & $\begin{array}{l}n \\
\tilde{m} \\
0 \\
\end{array}$ & $\stackrel{\infty}{\circ}$ & $\stackrel{3}{0}$ \\
\hline$\underline{\underline{E}}$ & 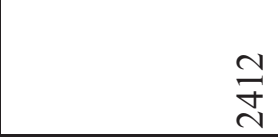 & $\vec{J}$ & 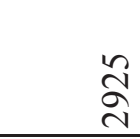 & $\underset{m}{\stackrel{0}{2}}$ \\
\hline 樆 & 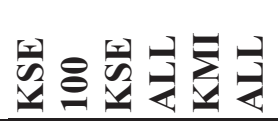 & 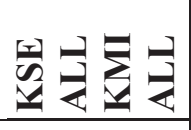 & 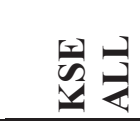 & $\begin{array}{ll}1 \\
0 \\
2\end{array}$ \\
\hline 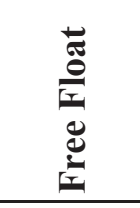 & $\begin{array}{l}8 \\
8 \\
8 \\
8 \\
0 \\
n \\
n\end{array}$ & $\begin{array}{l}8 \\
8 \\
i n \\
0 \\
0 \\
i\end{array}$ & $\begin{array}{l}\stackrel{0}{\infty} \\
\infty \\
\vec{\infty} \\
\infty\end{array}$ & $\begin{array}{l}8 \\
\stackrel{+}{+} \\
\stackrel{f}{+} \\
i \\
i\end{array}$ \\
\hline 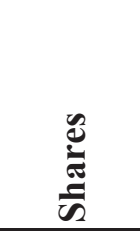 & $\begin{array}{l}8 \\
8 \\
8 \\
8 \\
8 \\
0 \\
0\end{array}$ & $\begin{array}{l}8 \\
8 \\
8 \\
8 \\
\dot{8} \\
\infty\end{array}$ & $\begin{array}{l}8 \\
\stackrel{N}{1} \\
\tilde{5} \\
\infty \\
+ \\
+\end{array}$ & 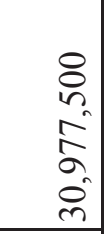 \\
\hline 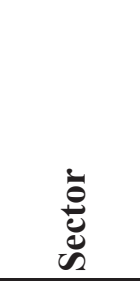 & 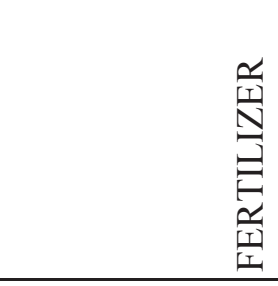 & 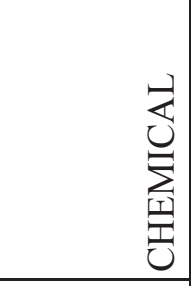 & 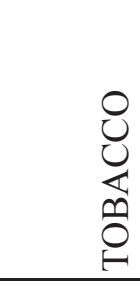 & 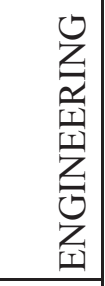 \\
\hline 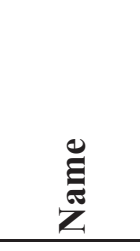 & 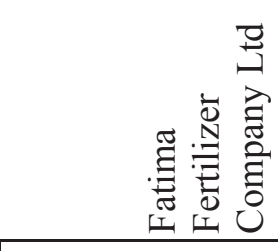 & 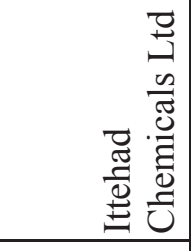 & 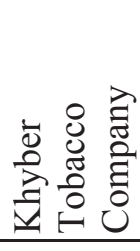 & 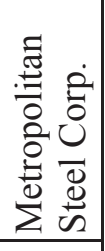 \\
\hline $\begin{array}{l}\overline{8} \\
\text { हे } \\
\text { हे }\end{array}$ & 氙 & 요 & : & $\begin{array}{l}\text { 리 } \\
\stackrel{\infty}{\infty}\end{array}$ \\
\hline
\end{tabular}


Findings for Indicator 9.c

In this subsection we will present findings of Tier I sub-sub indicator 9.c.1.

Findings for Indicator 9.c.1

This sub-sub indicator is measured by analysing data generated by question nine of PSLM 2014-15. The question asks if the household has a working telephone connection. The respondents that choose the third option (mobile) are of interest to us in measuring this indicator.

District specific data is presented in column 3 of Table 9. Specifically, we focused on question 9 of section G (Details of the Family) to estimate this sub-sub indicator. Findings of this sub-sub indicator are presented in column 5. Our findings show that Pakistan has a substantial (district wise) population covered by mobile networks.

TABLE 11

PROPORTION OF POPULATION COVERED BY A MOBILE NETWORK, BY TECHNOLOGY

\begin{tabular}{|l|l|l|l|l|}
\hline $\begin{array}{l}\text { Province } \\
\text { (1) }\end{array}$ & $\begin{array}{l}\text { District } \\
(\mathbf{2})\end{array}$ & $\begin{array}{l}\text { Mobile } \\
(\mathbf{3})\end{array}$ & $\begin{array}{l}\text { Total } \\
\text { Population } \\
\mathbf{( 4 )}\end{array}$ & $\begin{array}{l}\text { Proportion covered } \\
\text { by mobile network } \\
\mathbf{( 5 ) ( 3 / 4 )}\end{array}$ \\
\hline \multirow{4}{*}{ Punjab } & Attock & 730 & 792 & 92.17 \\
\cline { 2 - 5 } & Bahawalpur & 1622 & 1917 & 84.61 \\
\cline { 2 - 5 } & Lahore & 466 & 561 & 83.06 \\
\hline \multirow{5}{*}{ Sindh } & Badin & 1009 & 1306 & 77.25 \\
\cline { 2 - 5 } & Sukkur & 448 & 513 & 87.32 \\
\cline { 2 - 5 } & Karachi & 528 & 622 & 84.88 \\
\hline \multirow{5}{*}{ KPK } & Abbottabad & 395 & 451 & 87.58 \\
\cline { 2 - 5 } & Nowshera & 414 & 435 & 95.17 \\
\cline { 2 - 5 } & Peshawar & 358 & 399 & 89.72 \\
\hline \multirow{5}{*}{ Balochistan } & Sibbi & 228 & 296 & 77.02 \\
\cline { 2 - 5 } & Gwadar & 244 & 282 & 86.52 \\
\cline { 2 - 5 } & Quetta & 251 & 282 & 89.01 \\
\hline \multirow{2}{*}{} & & & \\
\hline
\end{tabular}

\section{CONCLUSION}

In the beginning of our study, we had raised three questions: first, how far does data poverty exist for the SDGs in Pakistan. Second, do specific Sustainable Development Goals, classified at tier 1 show large variation in data under the four criteria? Third, how could gaps on goals within tier 1 be addressed to tackle the measurement problem and improve the data collection process? 
This paper aimed to address these issues by developing an analytical framework to contextualize Pakistan's measurement of the Sustainable Development Goals (SDGs). In order to do so, we chose tier I SDG7 and SDG9 goals to demonstrate the variation in challenges within tier I goals within the same national context.

The choice to keep Tier I targets and focusing our analysis on specific Tier I indicators stemmed from the fact that the SDG Agenda 2030 was adopted by the Parliament of Pakistan, and the official UN Statistical Division's methodology on tiers allowed for methodological consistency. In doing so, we drew our analytical framework through a mapping exercise of goals and an assessment of nationally available data. In this first phase of our study, we found that 9 SDG Targets and their indicators had missing or partial data available. Next we analysed data sources for SDG indicators in the light of data availability, quality, granularity and accessibility. Last, an in-depth assessment of tier I indicators of SDG 7 and SDG 9 added to the academic debate on how best to measure the sustainable development goals under data constraints.

Through our findings, we hope to not only illustrate the unique challenges of measuring SDGs for developing countries in the light of data poverty, but to demonstrate a way forward for strengthening the collection of data for evidence, for the successful implementation of the SDGs. Despite the limitations and data gaps encountered during this study, by suggesting a diagnostic heuristic for SDG measurement, we hope to shed light on patterns of issues within SDG data, and wide variation within tier I targets and indicators.

Our study was not able to assess the status of all tier I indicators in Pakistan and future studies may be able to develop this methodology further in light of variation with tier I priorities for Pakistan. Moreover, measurement of SDGs may be affected by the interlinkages between the goals, their targets and their indicators, and future research may consider approaches that explore the complications of effective measurement under the constraint of interdependency.

\section{REFERENCES}

Ahmed, S. (2017). Functions of Provincial and District Authorities In Delivering the SDG: Lessons from Pakistan. Regional Knowledge Exchange . UNDP Pakistan.

Ariss, A., \& Manley, L. (2018). Strategies for SDG National Reporting. Center for Open Data Enterprise (CODE).

Asghar, Z., \& Umair, M. (2017). Expected Time to Achieve SDG 4.6: A Disaggregated Data Analysis for Pakistan. Munich Personal Repec Archive (MPRA). Retrieved from https://mpra.ub.unimuenchen.de/78327/

Bureau of Statistics, P. (2017). Multiple Indicator Cluster Survey 2017. Retrieved from http://www.bos.gop.pk/mics2017

Chen, S., Fonteneau, F., \& Jütting, J. (2013). Towards a post-2015 framework that counts: Development national statistical capacity. Paris21 Discussion Paper. Retrieved from http://mortenjerven.com/wpcontent/uploads/2013/04/Panel-8-Jutting.pdf

Christian Kroll, K. T-D. (2017). National baselines for the Sustainable Development Goals assessed in the SDG Index and Dashboards. Nature Geoscience. doi:10.1038/ngeo2985

David, M. (2018). Sustainable Development Goals (SDGs)-Challenges for India. Indian Journal of Public Health Research \& Development, 9(3). doi:10.5958/0976-5506.2018.00172.

Dickens, C., Smakhtin, V., McCartney, M., O’Brien, G., \& Dahir, L. (2019). Defining and Quantifying National-Level Targets, Indicators and Benchmarks for Management of Natural Resources to Achieve the Sustainable Development Goals, 11(462).

Equal Measures 2030. (2018). Data Driving Change. Introducing the EM2030 SDG Gender Index. Retrieved from https://data.em2030.org/wp-content/uploads/2018/09/EM2030-2018-GlobalReport.pdf

Faye, C., \& Kane, A. D. (2018). Leave no one behind: the challenges of collecting disaggregated data for SDGs. Southern Voice. 
Ghaus, K. A. (2016). Implications of Implementing SDGs at the National Level A Case of Pakistan. Southern Voice On Post-MDG International Development Goals, 32.

Gul, M., Mantegazza, I., \& Gul, E. (2018). Measuring Sustainable Development in Pakistan: Data Ecosystem for Agenda 2030. Research Gate. doi:10.13140/RG.2.2.16982.55361

Gurbo, M. (2017). Why are Sustainable Development Goals Important? Retrieved from https://idfi.ge/en/why_does_sdgs_matter

Hassan, Z. U. (2016). Presentation on Localising SDGs in Pakistan (Chief, Poverty Alleviation \& SDG Section). Islamabad: Ministry of Planning, Development \& Reform.

HDIP. (2018). Pakistan Energy Yearbook 2018. Islamabad: Hydrocarbon Development Institute of Pakistan.

Jacob, A. (2017). Mind the Gap: Analyzing the Impact of Data Gap in Millenium Development Goals (MDGs) Indicators on the progress towards MDGs. World Development, 93, 260-278. Retrieved from http://dx.doi.org/10.1016/j.worlddev.2016.12.016

Judd, K. (2016). 2030 Agenda and the SDGs: indicator framework, monitoring and reporting. Global Policy Watch. . Retrieved from https://www.2030agenda.de/sites/default/files/GPW10_2016_03_18.pdf

Kanbur, R., Patel, E., \& Stiglitz, J. (2015). Sustainable Development goals and measurement of economic and social progress.

Khan, A. J., \& Ali , W. (2019). Capacity Development Challenges in the way of SDGs implementation in Pakistan. Islamabad: Sustainable Development Policy Institute.

MacFeely, S. (2018). The 2030 Agenda: An Unprecedented Statistical Challenge. Research Gate. doi: 978-3-96250-213-3

Ministry of Finance- Government of Pakistan. (2018). Pakistan Economic Survey. Retrieved from http://www.finance.gov.pk/survey_1819.html

Nia, A. B., Hermouet, E., \& Shayani, D. (2019). Asia and the Pacific SDG Progress Report 2019. UNESCAP.

Pakistan Demographic and Health Survey (PDHS). (2017-2018). Pakistan Demographic and Health Survey (PDHS). National Institute of Population Studies and Macro International Inc.publication.

Pakistan, N. A. (2010). 18th Amendment: Constitution of Islamic Republic of Pakistan. Islamabad.

Pakistan, O. K. (2015). The State of Open Data in Pakistan. Retrieved from https://pk.okfn.org/2015/03/17/the-state-of-open-data-in-pakistan/

PARIS21. (2015). A scoring system to measure the use of statistics in the policy-making process. Retrieved from www.paris21.org/sites/default/files/Scoring_System_Use_Of_Data_2015_DFID.doc.

Patole, M. (2018). Localization of SDGs through Disaggregation of KPIs. Economies, 6(1), 15. doi:10.3390/economies6010015

Rahman, M. K. (2015). Measuring for Monitoring: The State of Datafor SDGs in Bangladesh. Dhaka: Southern Voice . Retrieved from http://www.post2015datatest.com/wpcontent/uploads/2015/09/Bangladesh-Country-Report-Final.pdf

Rasmussen, K., \& McArthur, J. W. (2019). Classifying Sustainable Development Goal trajectories: A country-level methodology for identifying which people and issues are getting left behind. World Development.

Sachs, J. D. (2012). From Millennium Development Goals to Sustainable Development Goals. Lancet, 2206-11.

Sachs, J., Delacre, D., Kroll, G., \& Teksoz, K. (2018). SDG Index and Dashboards Report: Country Profiles. New York: Bertelsmann Stiftung and Sustainable Development Solutions Network. Retrieved from https://s3.amazonaws.com/sustainabledevelopment.report/2018/2018_sdg_index_and_dashboards _country_profiles.pdf

Schiltz, $\bar{A}$. M. (2019). Measuring sustainable development goals performance: How to monitor policy action in the 2030 Agenda implementation? Ecological Economics, (106373).

34 Journal of Strategic Innovation and Sustainability Vol. 15(1) 2020 
Statistics, P. B. (2015). Pakistan Social And Living Standards Measurement. PBS.

Umar, M. (2018). SDG Index for Pakistan at Provincial Level. Munich Personal Repec Archive, (83997). Retrieved from https://mpra.ub.uni-muenchen.de/83997/1/MPRA_paper_83997.pdf

UNDP. (2016). Swaziland Data Ecosystem Mapping Report. UNDP. Retrieved from https://www.undp.org/content/dam/2030agenda/Publications/data-for-development/Swaziland/

UNDP \& Pakistan Ministry of Planning, Development and Reform. (2018). Data Reporting Gaps: Pakistan's Perspective. Retrieved from https://www.sdgpakistan.pk/uploads/pub/Data_Reporting_Gaps.pdf

UNESCAP. (2016). Achieving the Sustainable Development Goals in South Asia:Key Policy Priorities and Implementation Challenges. United Nations ESCAP. Retrieved from https://www.unescap.org/publications/achieving-sustainable-development-goals-south-asia-k

UNESCAP. (2017). Measuring SDG progress in Asia and the Pacific: Is there enough data? United Nations: Economic and Social Comission for Asia and Pacific.

UNESCAP. (2019). Asia and the Pacific SDG Progress Report 2019. United Nations Economic and Social Commission for Asia and the Pacific (ESCAP).

United Nations. (2017). Why the SDGs Matter? Retrieved from United Nations: Sustainable Development Goals: https:/www.un.org/sustainabledevelopment/why-the-sdgs-matter/

United Nations DESA. (2018). International Recommendations for Energy Statistics (IRES). Department of Economic and Social Affairs Statistics Division. New York: United Nations.

United Nations Development Group. (2018). The Sustainable Development Goals Are Coming to Life Stories of Country Implementation and UN Support (Pakistan). United Nations Development Group.

United Nations Statistics Division. (2018). Institutional Information Concepts and Definitions. United Nations. Retrieved from https://unstats.un.org/sdgs/files/Overview\%20of\%20Standards\%20for\%20Data\%20Disaggregatio n.pdf

USAID, N. I. (2018). Pakistan Demographic and Health Surveys 2017-18. National Institute of Population Studies.

World Bank. (2017). Statistical Capacity- Pakistan. [Online]. Retrieved from https://data.worldbank.org/indicators/IQ.SCI.OVRL?end=2017\&locations=PK\&Start=2004\&vie $\mathrm{w}=$ chart

World Bank. (2019). Enterprise Surveys.

World Bank, IEA \& ESMAP. (2019). SE4ALL Global Tracking Framework . World Bank. 